\title{
Rancang Bangun Visualisasi Usulan Penduduk Kota Surabaya Pada Situs Monvis-Musrenbang Surabaya
}

\author{
Danding Prawira Erawan Hakam dan Faisal Johan Atletiko \\ Departemen Sistem Informasi, Fakultas Teknologi dan Informasi, Institut Teknologi Sepuluh Nopember (ITS) \\ e-mail: atletiko@gmail.com
}

\begin{abstract}
Abstrak-Pemerintah kota Surabaya, memiliki sebuah situs berfungsi untuk memudahkan pemerintah menampung usulan rencana pembangunan dari masyarakat. Situs tersebut juga memberikan informasi kepada masyarakat tentang tanggapan pemerintah terhadap usulan - usulan pembangunan yang telah diajukan oleh masyarakat. Akan tetapi, status dari usulan tersebut belum bisa dievaluasi secara langsung oleh masyarakat melalui situs Musrenbang. Oleh karena itu, perlu dibuat sistem yang dapat digunakan oleh masyarakat untuk mengevaluasi secara langsung setiap usulan yang masuk pada Musrenbang. Situs Monitoring dan Visualisasi Musrenbang atau disebut Monvis-Musrenbang merupakan situs untuk memonitoring hasil Musyawarah Rencana Pembangunan (Musrenbang) Kota Surabaya. Melalui situs ini masyarakat bisa dengan lebih mudah melihat usulan - usulan pembangunan yang masuk ke dalam situs Musrenbang. Masyarakat juga bisa memasukkan penilaian terhadap setiap usulan pembangunan, mengirimkan pesan kepada SKPD terkait, dan memberikan komentar pada usulan. Selain melalui sistem situs, masyarakat juga bisa memberikan masukan tentang usulan melalui sosial media yang dimiliki. Tidak hanya warga masyarakat, pihak pemerintah juga bisa memberikan tanggapan pada setiap usulan melalui situs. Dari masukan - masukan yang diberikan oleh masyarakat tersebut, situs dapat kemudian akan mengolah masukan-masukan tersebut menjadi informasi yang menunjukkan apakah Pemerintah Kota Surabaya telah menjalankan usulan pembangunan dengan baik sebagai monitoring terhadap usulan-usulan yang ada pada Musrenbang. Semakin banyak warga masyarakat yang berpartisipasi untuk memberikan masukan terhadap usulan, maka hasil dari monitoring yang dilakukan juga semakin akurat. Oleh karena itu, situs harus melakukan sesuatu untuk meningkatkan partisipasi masyarakat tersebut. Penerapan teknik untuk situs Monitoring dan Visualisasi Musrenbang diharapkan dapat meningkatkan dan mempertahankan aktivitas pengguna situs dengan cara memotivasi pengguna untuk terus memberikan masukan pada sistem Monitoring dan Visualisasi Musrenbang.
\end{abstract}

Kata Kunci-Monvis-Musrenbang, Surabaya Dalam Angka, Google Maps.

\section{PENDAHULUAN}

$\mathrm{P}$ EMERINTAHAN kota Surabaya memiliki sebuah situs online yang menampung aspirasi kebutuhan warga Surabaya. Situs tersebut mempunyai fungsi untuk mempermudah masyarakat mendapatkan informasi tentang

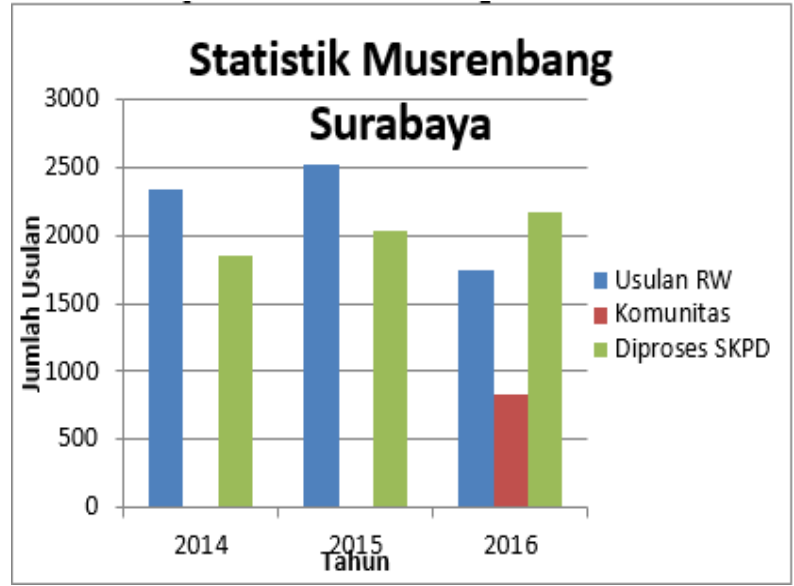

Gambar 1. Statistik pada Musrenbang Surabaya.

tanggapan pemerintah. Pada fitur tersebut menyediakan system bagi warga Surabaya untuk dapat memberikan nilai, mengirim pesan, dan memberikan komentar pada setiap usulan yang ada pada situs Musrenbang Surabaya milik Pemerintah Kota Surabaya. Situs ini hanya memberikan informasi tentang usulan dari setiap wilayah (kelurahan) yang ada. Namun, musrenbang tidak menampilkan data tentang kondisi masyarakat yang sudah tercatat pada Surabaya Dalam Angka.

Surabaya Dalam Angka pertama kali dipublikasikan pada tahun 2002 oleh Badan Pusat Statistik (BPS) Kota Surabaya. Tujuan dipublikasikannya buku tersebut adalah untuk membantu persediaan data di tingkat Kota. Sehingga bermanfaat sebagai data pendukung untuk penyusunan, perencanaan, kebijaksanaan, dan evaluasi pembengunan di wilayah kecamatan sekaligus sebagai data pendukung pembangunan wilayah Kota Surabaya. Surabaya Dalam Angka adalah gambaran umum yang menjelaskan tentang keadaan ekonomi, sosial, demografi, pelaksanaan pembangunan dan gerak perubahannya di seluruh sektor di Surabaya. Data yang disajikan dapat digunakan sebagai informasi dasar oleh seluruh lapisan masyarakat untuk berperan serta memantapkan perencanaan, evaluasi, dan pengendalian pembangunan sebagai upaya mendukung otonomi kota Surabaya, untuk memastikan kesinambungan antara proposal yang diajukan pada Musrenbang Surabaya dengan keadaan masyarakat yang ada dalam Surabaya Dalam Angka pada tahun 2015. Contohnya Potensi Pertahanan Sipil menurut Jenis Latihan pada Kecamatan Tegalsari terdapat 648 penduduk yang belum terlatih. Hal ini berkaitan dengan usulan Pelatihan Satpam yang diajukan oleh kecamatan tersebut. Sehingga perlu di visualisasikan pada Monvis-Musrenbang. 
Gambar 1 menjelaskan banyaknya jumlah usulan yang ada pada tahun 2014, 2015 hanya ada usulan RW dan diproses SKPD. Dan tapada tahun 2016 tumbuhnya usulan pada komunitas dan usulan RW menurun.

\section{URAIAN PENELITIAN}

\section{A. Perumusan dan Batasan Masalah}

Berdasarkan uraian latar belakang di atas, maka rumusan permasalahan yang menjadi fokus dan akan diselesaikan dalam Studi ini antara lain :

1. Bagaimana cara mengintegrasikan data yang ada di Surabaya Dalam Angka dengan data yang ada di emusrenbang surabaya.

2. Bagaimana cara memvisualis asikan antara Surabaya Dalam Angka dan Musrenbang dalam situs Monvis-Musrenbang.

Studi ini tidak membahas rancang bangun situs Monitoring dan Visualisasi Musrenbang dari awal melainkan hanya berfokus pada penerapan teknk visualisasi yang terkait antara data e-Musrenbang Surabaya dengan Surabaya dalam angka.

\section{B. Tujuan dan Manfaat Penelitian}

Berdasarkan hasil perumusan masalah dan batasan masalah yang telah disebutkan sebelumnya maka tujuan yang dicapai dari Studi ini adalah diterapkannya integrasi dan memvisualisasi pada situs Monitoring dan Visualisasi Musrenbang Surabaya agar pengguna dapat mengetahui informasi tentang keterkaitan usulan yang diajukan dari musrenbang dengan kondisi masyarakat yang terdapat pada Surabaya Dalam Angka.

Manfaat yang diberikan dengan adanya Studi ini adalah sebagai berikut:

1. Dapat menampilkan informasi secara visual untuk memudahkan analisa pemerintah dalam kasus ada tidaknya keterkaitan antara data pada Musrenbang Surabaya dengan Surabaya Dalam Angka.

2. Dapat memberikan informasi kepada masyarakat tentang keterkaitan antara data yang berasal dari Surabaya Dalam Angka dengan data dari e-Musrenbang Surabaya secara Visual dalam situs Monis-Musrenbang

Hasil visualisasi yang diberikan oleh situs menjadi lebih akurat.

\section{Dasar Teori}

Musrenbang adalah singkatan dari Musyawarah Perencanaan Pembangunan. Musrenbang merupakan agenda tahunan yang memfasilitasi warga untuk saling bertemu dan mendiskusikan masalah yang mereka hadapi di setiap daerah dengan tujuan agar dapat memutuskan prioritas pembangunan jangka pendek, untuk selanjutnya akan diusulkan kepada pemerintah pada tingkat lebih tinggi. Melalui badan perencanaan (BAPPEDA) usulan masyarakat dikategorisasikan berdasar urusan dan alokasi anggaran [1]. Dalam membantu pelaksanaan Musrenbang, kota Surabaya memiliki situs web yaitu e-Musrenbang. Melalui e-Musrenbang ini masyarakat dapat memonitoring daftar usulan yang telah disetujui maupun yang ditolak dari tiap tahunnya. Untuk dapat menyampaikan pendapat tentang usulan yang diajukan berupa like, dis like dan komentar pada situs e-Musrenbang ini masyarakat dapat mengakses dengan user umum namun hanya warga yang berKTP Surabaya dengan login menggunakan NIK. Tidak seluruh warga surabaya dapat menginput usulan melalui situs ini, namun warga dapat menyampaikan usulan tersebut melalui ketua RW setempat untuk selanjutnya dapat diinput pada eMusrenbang tersebut. Selain ketua RW yang dapat melakukan input usulan pada sistem ini hanyalah tim RW, Kelurahan, Kecamatan, SKPD, dan Bappeko Surabaya [2].

Tahapan penyampaian usulan dari warga dimulai dari tingkat RW dengan melaksanakan musyawarah warga yang juga membentuk tim yang bertugas untuk melakukan input usulan yang telah disepakati. Tim yang dapat melakukan input usulan mempunyai user dan password login masing-masing. Setiap tim RW setempat dapat mengisikan maksimal 2 usulan utama dan 1 usulan cadangan. Usulan yang telah disepakati tersebut untuk selanjutnya dikirimkan ke Kelurahan. Tugas kelurahan memilih usulan-usulan RW (dibatasi pagu) dengan memberikan keterangan yang lebih mendetail tentang usulan tersebut untuk selanjutnya dikirim ke tingkat kecamatan. Melalu kecamatan ini usulan tersebut akan dilakukan penentuan bahwa usulan yang diajukan diterima atau ditolak. Usulan yang diterima untuk selanjutnya akan dilakukan survey oleh SKPD. Hasil akhir dari tahapan tersebut merupakan daftar usulan yang disetujui dan usulan yang di tolak yang kemudian ditampilkan pada situs eMusenbang [3]. (Gambar 2)

Surabaya Dalam Angka [4] merupakan publikasi statistik tahunan pada Badan Pusat Statistik (BPS) Kota Surabaya yang menyajikan kumpulan data dari berbagai sumber secara komperhensif, dilengkapi dengan penjelasan teknis. Publikasi tersebut bertujuan untuk memberikan informasi statistik seluruh sector di Surabaya setiap tahun. Surabaya Dalam Angka memaparkan tentang berbagai aspek yang terkait dengan keadaan Kota Surabaya yang diantaranya adalah kondisi geografis Kota Surabaya; Pemerintahan dan Pertahanan Keamanan; kependudukan (mutasi penduduk, tenaga kerja, dan keluarga berencana); sosial budaya; Kesehatan dan Kebersihan; Agama; Sosial lainnya; Pertanian; Peternakan; Perikanan; Industri; Kebutuhan masyarakat (Listrik, Gas dan Air minum); Perdagangan; Perhubungan, Perhotelan Hiburan dan Wisata; serta Perekonomian [4].

Monvis Musrenbang atau Monitoring dan Visualisasi Musrenbang merupakan situs berbasis web yang dibuat dengan tujuan dapat mempermudah masyarakat umum dalam melakukan monitoring, mengevaluasi dan menyampaikan aspirasinya yang telah terdaftar dalam e-Musrenbang kepada Pemerintah Kota Surabaya. Selain itu melalui Monvis Musrenbang ini pemerintah dapat dengan mudah memberikan laporan progress serta transparansinya dalam mendukung terselenggaranya open government yang baik. Monvis musrenbang merupakan riset yang dikelola oleh Laboratorium Akuisisi Data dan Diseminasi Informasi, Jurusan Sistem Informasi ITS [5]. Melalui aplikasi ini diharapkan dapat meningkatkan kesadaran warga Surabaya tentang perkembangan pembangunan Surabaya sehingga dapat membantu pemerintah dalam menentukan kebijakan yang lebih 


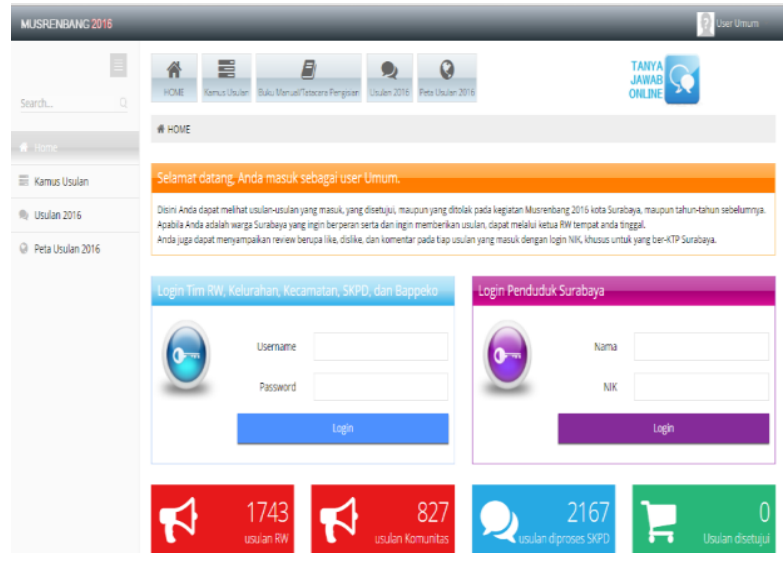

Gambar 2. Tampilan e-Musrenbang.

baik berkaitan dengan masyarakat dan pengembangan kota. Melalui aplikasi ini juga menunjukkan transparansi terhadap proyek pembangunan pemenintah baik fisik maupun nonfisik di kota, kabupaten dan desa [6].

\section{ETL (Extract, Transform, Load)}

merupakan kumpulan proses menyiapkan data dari operational source untuk data. Proses ini terdiri dari extracting, transforming, loading, dan beberapa proses yang dilakukan sebelum dibuat dan dipublikasikan dalam bentuk data warehouse. Dengan kata lain, ETL adalah tahap untuk memproses data dari sumber data untuk masuk ke dalam data warehouse. Tujuan ETL adalah mengumpulkan, menyaring, mengolah dan menggabungkan data-data yang relevan dari berbagai sumber untuk disimpan ke dalam data warehouse. ETL juga dapat digunakan untuk mengintegrasikan data dengan sistem yang sudah ada sebelumnya [7].

\section{E. Google Maps}

Google Maps adalah sebuah situs peta gratis dan online tersebut dikembangkan oleh google sendiri yang dapat ditemukan di http:maps.google.com. Pada situs tersebut kita dapat melihat inforgeografis pada seitap wilayah dimuka bumi. Layanan ini interaktif karena di dalam peta tersebut dapat digeser sesuai keinginan pengguna, mengubah tingkat zoom, serta mengubah tampilan pada peta tersebut. Google maps juga menawarkan peta yang dapat diseret dan gambar dari satelit untuk seluruh dunia, serta menawarkan rute perjalanan [8].

Adanya fasilitas sebagai mesin pencari pada layanan gmap, tentu sangat membantu para pengguna internet [9]. Hal ini khususnya dalam proses pencarian sebuah lokasi yang lebih tepat dan agak asing. Karena dengan adanya perangkat lunak ini akan memberikan beberapa kegunaan diantaranya adalah mempercepat pencarian suatu lokasi dalam waktu yang singkat. Karena dengan tekhnologi digital system pencarian akan berlangsung dengan cepat.

\section{F. Visualisasi}

Sebuah pengungkapan dari suatu gagasan atau persaan dengan menggunakan gambar, tulisan dalam bentuk kata dan angka, peta, grafik dan lainnya. Data dari sistem informasi dapat dibuat agar lebih mudah dipahami dan dugunakan dengan grafis, diagram, label, peta, gambar digital, presentasi tiga dimensi, animasi dan teknologi visualisasi data lainnya [10]. Terdapat dua konsep visualisasi, yaitu scientific visualisation dan information visualisation. kedua konsep tersebut membuat model grafis dan menyajikan data seecara visual yang berinteraksi langsung dengan pengguna untuk melakukan eksplorisasi dan memperoleh informasi yang terdapat dalam data scientific visualisation, pada umumnya model grafis dibangun dari pengukuran atau simulasi data yang mewakili objek atau konsep yang terkait dengan fenomena yang sebenarnya. Pada information visualisation konsep abstrak dan hubungan yang tidak selalu memiliki keterkaitan di dunia nyata [11]. Menurut [12] tujuan utama dari visualisasi data adalah untuk mengkomunikasikan informasi secara jelas dan efisien kepada pengguna lewat grafik informasi yang dipilih, seperti tabel dan grafik. visualisasi yang efektif dapat membantu pengguna dalam menganalisa dan penalaran tentang data dan bukti. Visualisasi data dapat membuat data yang kompleks bisa diakses, dipahami dengan mudah dan berguna bagi penggunanya, sehingga pengguna bisa melakukan analisis tertentu seperti melakukan pembandingan atau memahami kausalitas, dan prinsip perancangan dari grafik mengikuti pekerjaan tersebut.

\section{G. SIPDIS}

Surabaya Integrated Planning and Development Information Sistem atau S.I.P.D.I.S merupakan aplikasi sistem informasi geografis yang berisikan peta Surabaya dalam bentuk Real. S.I.P.D.I.S dibuat untuk melengkapi sistem Musrenbang Surabaya dalam hal pembuatan detail usulan. Usulan yang menggunakan aplikasi ini biasanya berupa usulan yang berbentuk fisik dan non fisik seperti perbaikan jalan, pembangunan jembatan, dan lain-lain.

Setiap user yang memasukkan usulan berupa usulan fisik akan diminta menggambarkan detail usulan pada sistem Musrenbang (yang membuat peta hanya di tingkat kelurahan), detail usulan yang digambarkan misalnya berapa panjang jalan yang akan diperbaiki. Aplikasi S.I.P.D.I.S akan menyimpan data detail usulan.

\section{PETUNJUK TAMBAHAN}

\section{A. Studi Literatur}

Pada tahap ini, penulis melakukan studi literatur tentang Surabaya Dalam Angka dan Musrenbang Surabaya penelitan yang telah dilakukan sebelumnya yang terkait dengan topik Studi ini. Hasil yang diharapkan pada tahapan ini adalah pemahaman tentang konsep dan langkah-langkah yang benar dalam pengerjaan Studi ini.

\section{B. Identifikasi Kebutuhan}

Pada tahap ini, penulis akan melakukan studi terkait dengan lingkungan sistem Musrenbang, Surabaya Dalam Angka dan sistem Monvis-Musrenbang yang telah dibuat dan dikembangkan. Hasil yang diharapkan dari proses ini adalah rancangan daftar kebutuhan yang didokumentasikan untuk digunakan pada pengembangan aplikasi. 
Tabel 1.

Daftar aktivitas yang bisa dilakukan pada sistem

\begin{tabular}{|c|c|c|c|}
\hline \multicolumn{2}{|c|}{ Aktivitas } & \multicolumn{2}{|c|}{ Tujuan } \\
\hline \multicolumn{2}{|c|}{ Registrasi } & \multicolumn{2}{|c|}{$\begin{array}{c}\text { Memperoleh akun pengguna pada dinas yang digunakan } \\
\text { untuk login pada sistem yang bias dilakukan oleh } \\
\text { admin. }\end{array}$} \\
\hline \multicolumn{2}{|c|}{ Login } & \multicolumn{2}{|c|}{$\begin{array}{c}\text { Melakukan aktivitas - aktivitas yang membutuhkan } \\
\text { login (mengirim komentar, memberi } \\
\text { tanggapan/membalas) }\end{array}$} \\
\hline \multicolumn{2}{|c|}{$\begin{array}{c}\text { Kirim } \\
\text { komentar }\end{array}$} & \multicolumn{2}{|c|}{ Mengirimkan komentar mengenai usulan tertentu. } \\
\hline \multicolumn{2}{|c|}{$\begin{array}{l}\text { Share media } \\
\text { sosial }\end{array}$} & \multicolumn{2}{|c|}{ Membagikan alamat situs melalui media sosial } \\
\hline \multicolumn{2}{|c|}{ Like komentar } & \multicolumn{2}{|c|}{$\begin{array}{l}\text { Menyatakan kesetujuan atau ketidaksetujuan pengguna } \\
\text { terhadap komentar tertentu }\end{array}$} \\
\hline \multicolumn{2}{|c|}{$\begin{array}{l}\text { Menjawab } \\
\text { komentar }\end{array}$} & \multicolumn{2}{|c|}{ Memberikan jawaban terhadap salah satu komentar. } \\
\hline \multicolumn{2}{|c|}{$\begin{array}{l}\text { Memperbarui } \\
\text { progres usulan }\end{array}$} & \multicolumn{2}{|c|}{$\begin{array}{l}\text { SKPD menyampaikan informasi progres pengerjaan } \\
\text { pembangunan kepada masyarakat. }\end{array}$} \\
\hline \multicolumn{4}{|c|}{$\begin{array}{c}\text { Tabel } 2 . \\
\text { Hasil analisis pengguna sistem }\end{array}$} \\
\hline \multicolumn{2}{|l|}{$\begin{array}{c}\text { Penggu } \\
\text { na }\end{array}$} & Deskripsi & Aktivitas \\
\hline $\begin{array}{c}\text { Masyar } \\
\text { akat }\end{array}$ & \multicolumn{2}{|c|}{$\begin{array}{l}\text { Masyarakat berperan untuk } \\
\text { memberikan tanggapan } \\
\text { terhadap usulan - usulan } \\
\text { yang disajikan oleh sipdis. } \\
\text { Satuan Kerja Perangkat } \\
\text { Daerah adalah pihak yang } \\
\text { bertanggung jawab terhadap } \\
\text { pelaksanaan setiap usulan. }\end{array}$} & $\begin{array}{c}\text { Menjelajah usulan. } \\
\text { Mengirim komentar. } \\
\text { Memberikan penilaian. } \\
\text { Like Komentar. } \\
\text { Share media sosial. } \\
\text { Melihat pesan yang dikirim } \\
\text { oleh masyarakat. } \\
\text { Menanggapi pesan yang } \\
\text { disampaikan oleh } \\
\text { masyarakat. } \\
\end{array}$ \\
\hline \multicolumn{4}{|c|}{$\begin{array}{l}\text { Tabel } 3 . \\
\text { SIPDIS }\end{array}$} \\
\hline \multicolumn{2}{|c|}{ Nomor SKPL } & \multicolumn{2}{|c|}{ Kebutuhan Non Fungsional } \\
\hline \multicolumn{2}{|c|}{ NFR-01 } & \multicolumn{2}{|c|}{$\begin{array}{c}\text { Usability - Sistem sipdis dapat dengan mudah } \\
\text { digunakan oleh pengguna dan dapat memenuhi } \\
\text { kebutuhan. }\end{array}$} \\
\hline \multicolumn{2}{|c|}{ NFR-02 } & \multirow{2}{*}{\multicolumn{2}{|c|}{$\begin{array}{l}\text { Portability - Desain sipdis harus responsive, desain } \\
\text { bisa berubah sesuai dengan ukuran layar perangkat } \\
\text { yang mengakses. } \\
\text { Performance - Sistem memiliki performa yang } \\
\text { tinggi, dinilai dari banyaknya menyimpan data. }\end{array}$}} \\
\hline NFR- & & & \\
\hline
\end{tabular}

\section{Perancangan Aplikasi}

Pada tahap ini, penulis akan melakukan studi terkait deng an lingkungan sistem Musrenbang, Surabaya Dalam Angka dan sistem Monvis-Musrenbang yang telah dibuat dan dikembangkan.

\section{Pembuatan Aplikasi}

Yang dibutuhkan untuk mengembangkan aplikasi dan rancangan alur lalu-lintas data pada setiap sistem, pada tahap ini dilakukan perubahan pada aplikasi Monvis Musrenbang untuk menyesuaikan sistem ini terhadap rancangan yang dibuat agar dapat data pada setiap sistem dapat terintegrasi dengan baik. Hasil yang diharapkan pada tahap ini adalah aplikasi Monvis Musrenbang yang telah siap untuk diintegrasikan. (Tabel 1)
Tabel III.

Daftar analisis pengguna dan aktivitas pengguna

\begin{tabular}{|c|c|c|}
\hline Pengguna & Deskripsi & Aktivitas \\
\hline Masyarakat & $\begin{array}{c}\text { Masyarakat } \\
\text { berperan untuk } \\
\text { memberikan } \\
\text { tanggapan terhadap } \\
\text { usulan - usulan } \\
\text { yang disajikan oleh } \\
\text { situs. }\end{array}$ & $\begin{array}{c}\text { - Melihat usulan- } \\
\text { usulan yang ada } \\
\text { - Memberikan } \\
\text { komentar terhadap } \\
\text { usulan } \\
\text { - Memberikan like } \\
\text { pada komentar } \\
\text { - Share ke media } \\
\text { sosial }\end{array}$ \\
\hline SKPD & $\begin{array}{c}\text { Satuan Kerja } \\
\text { Perangkat Daerah } \\
\text { adalah pihak yang } \\
\text { bertanggung jawab } \\
\text { terhadap } \\
\text { pelaksanaan setiap } \\
\text { usulan. }\end{array}$ & $\begin{array}{c}\text { - Melihat pesan yang } \\
\text { dikirim oleh } \\
\text { masyarakat } \\
\text { - Menanggapi pesan } \\
\text { yang disampaikan } \\
\text { oleh masyarakat. } \\
\text { - Edit progres usulan }\end{array}$ \\
\hline Administrator & $\begin{array}{l}\text { Pengelola situs } \\
\text { yang juga } \\
\text { bertanggung jawab } \\
\text { dalam mengelola. }\end{array}$ & $\begin{array}{c}\text { - Membuat mekanisme } \\
\text { - } \text { Menghapus } \\
\text { mekanisme } \\
\text { - Mengubah } \\
\text { mekanisme } \\
\end{array}$ \\
\hline
\end{tabular}

Tabel 5.

Daftar kebutuhan fungsional sistem

\begin{tabular}{cc}
\hline \hline $\begin{array}{c}\text { Nomor } \\
\text { SKPL }\end{array}$ & Kebutuhan Fungsional \\
\hline FR-01 & Sistem bisa menampilkan usulan yang ada. \\
FR-02 & Sistem bisa memberikan komentar pada usulan \\
FR-03 & Sistem bisa memberikan Like pada komentar \\
FR-04 & Sistem bisa Share ke sosial media \\
FR-05 & Administrator dan SKPD dapat melakukan sistem \\
& Login \\
FR-06 & SKPD dapat mengelola usulan yang ada \\
FR-07 & Administrator dapat membuat mekanisme usulan baru \\
FR-08 & Administrator bisa melihat aktivitas pengguna \\
FR-9 & Administrator bisa mengubah mekanisme usulan \\
FR-10 & Administrator bisa menghapus mekanisme usulan \\
\hline \hline
\end{tabular}

Tabel 6.

Daftar kebutuhan non fungsional sistem

Kebutuhan Non Fungsional

Usability - Sistem sipdis dapat dengan mudah digunakan oleh pengguna dan dapat memenuhi kebutuhan.

Portability - Desain sipdis harus responsive, desain bisa berubah sesuai dengan ukuran layar perangkat yang mengakses.

Performance - Sistem memiliki performa yang tinggi, dinilai dari banyaknya menyimpan data.

\section{E. Pengujian Aplikasi}

Pada tahap ini dilakukan uji fungsional dan responsif web yang nantinya dapat berjalan sesuai dengan rancangan yang dibangun.

\section{F. Analisis Konteks}

Analisis konteks dilakukan dengan observasi pada sistem, pengguna, dan lingkungan yang berhubungan dengan sistem. Observasi dilakukan dengan cara survei mengenai 
Musrenbang kepada Badan Perencanaan Pembangunan Kota dan diskusi dengan pengembang situs Monitoring dan Visualisasi Musrenbang. Berikut adalah hasil analis is konteks berdasar observasi.

a. Intent

Tujuan diterapkannya metode ini dapat diperoleh dari manfaat Studi ini, yaitu:

1. Terpenuhinya kebutuhan masukan untuk sistem situs Monitoring dan Visualisasi Musrenbang untuk jangka waktu yang panjang.

2. Lebih banyak masyarakat yang ingin berpartisipasi dalam kegiatan monitoring musrenbang.

3. Hasil monitoring yang diberikan oleh situs menjadi lebih akurat dan terbarukan.

b. Situation

Berikut adalah situasi yang berlaku pada sistem.

1. Sistem tergolong sistem pekerjaan karena membutuhkan keserius an dari penggunanya, bukan sebagai hiburan.

2. Kebutuhan masukan sistem berubah - ubah dari waktu ke waktu, misalnya untuk fase pengenalan, sistem membutuhkan banyak pengguna yang membagikan alamat sistem melalui media sosial. Sedangkan saat sistem sudah dikenal masyarakat, sistem membutuhkan banyak masukan mengenai usulan.

3. Sistem digunakan oleh masyarakat untuk menyampaikan informasi dan penilaian masyarakat terhadap pelaksanaan pembangunan. Sedangkan SKPD menggunakan sistem untuk memberikan informasi kepada masyarakat terkait dengan pembangunan yang dilaksanakan.

4. Motivasi masyarakat untuk memberikan informasi dan penilaian didapatkan dari kepedulian masyarakat.

c. Task

Error! Reference source not found. 1 menunjukkan daftar aktivitas yang dilakukan pengguna di dalam sistem beserta tujuan aktivitas tersebut.

$d$. User

Error! Reference source not found. menunjukkan hasil observasi terhadap pengguna dan aktivitas apa yang dilakukan pengguna melalui sistem.

\section{G. Analisis Kebutuhan}

Analisis kebutuhan dilakukan untuk mendapatkan kebutuhan fungsional dan non-fungsional system.

Penerapan SIPDIS pada situs Monitoring dan Visualisasi Musrenbang berfungsi untuk meningkatkan dan mempertahankan aktivitas pengguna dalam memberikan masukkan pada usulan. Dari sisi pengguna situs, SIPDIS harus bisa menarik pengguna agar tetap memberikan masukkan dan meningkatkan aktivitasnya (Tabel 3). Sedangkan dari sisi pengelola situs, penerapan harus memberikan fasilitas pada pengelola untuk mengelola sistem pada situs. Pengelolaan sistem berupa mengelola aktivitas pengguna, membuat, mengubah, dan menghapus mekanisme sipdis. Berikut adalah pengguna yang akan sistem menggunakan fitur SIPDIS pada situs Monvis-Musrenbang. Dalam dokumen ini, pengguna juga disebut sebagai aktor. (Tabel 4)

\section{H. Kebutuhan Fungsional}

Kebutuhan fungsional dari sistem SIPDIS yang diterapkan pada situs Monvis-Musrenbang ditunjukkan pada Tabel 5. Kebutuhan fungsional adalah kebutuhan yang terkait dengan fitur atau fungsi sistem. Kebutuhan fungsional yang disebutkan pada tabel tersebut hanya kebutuhan fungsional untuk sistem SIPDIS saja. Sedangkan kebutuhan fungsional untuk situs Monvis-Musrenbang tidak termasuk dalam cakupan Studi ini, sesuai dengan batasan Studi.

\section{Kebutuhan Non Fungsional}

Tabel6 menunjukkan kebutuhan Non Fungsional dari sistem. Kebutuhan non fungsional adalah kebutuhan yang berkaitan dengan kualitas sistem. Kebutuhan non fungsional pada Studi ini hanya kebutuhan untuk sistem saja. Sedangkan kebutuhan untuk situs Monvis-Musrenbang tidak perlu diperhatikan, sesuai dengan batasan Studi.

\section{J. Desain Perangkat Lunak}

Desain perangkat lunak dibuat berdasarkan kebutuhan fungsional dan non fungsional yang telah diperoleh sebelumnya. Desain perangkat lunak dibuat sebagai acuan untuk implementasi.

1) Use Case

Pada tahap ini menjelaskan apa saja yang bisa dilakukan admin dan yang lainnya. Admin bisa melakukan login, mengelola kecamatan, mengelola kelurahan, mengelola usulan, mengelola SKPD, mengelola data login SKPD.

\section{IMPLEMENT ASI}

Menjelaskan terkait proses implementasi pada perangkat lunak yang dirancang. Pada bagian ini akan dijelaskan bagaimana lingkungan implementasi, pembuatan fitur - fitur aplikasi dan proses pengujian aplikasi.

Beberapa hal yang penting diperhatikan oleh penulis :

1) Lingkungan Implementasi

2) Pembuatan aplikasi, meliputi desain interface, untuk admin, masyarakat dan SKPD

\section{KESIMPULAN/RINGKASAN}

Pada bab ini akan diuraikan kesimpulan dan saran berdasarkan implementasi yang telah dilakukan dan hasil yang telah diperoleh pada Studi. Sistem sudah bisa berfungsi dengan baik sesuai dengan kebutuhan fungsional maupun non fungsional. Terbukti hasil pengujian fungsional dan non fungsional yang berjalan dengan baik. Berikut adalah saran dari penulis yang bermanfaat untuk penelitian selanjutnya. Saran dibuat berdasarkan pengalaman penulis selama melakukan penelitian. Untuk pembuatan desain, yang perlu diperhatikan adalah situasi sistem dan pengguna sistem. Kedua elemen tersebut menentukan efisiensi dan efektivitas yang diterapkan. Implementasi sebaiknya memperhatikan desain dari sistem induk yang akan ditambahkan. Implementasi sipdis tidak boleh merusak performa sistem. 


\section{DAFTAR PUSTAKA}

[1] Solokotakita.org, "Solo Kota Kita, Apa Itu Musrenbang?" .

[2] Bappeko Surabaya, "Halaman Utama Musrenbang 2016," Surabaya, 2016.

[3] Bappeko Surabaya, "User Manual Pengisian Musrenbang 2016," Surabaya, 2016.

[4] Badan Pusat Statistik, "Surabaya Dalam Angka 2014," Surabaya, 2014

[5] Monvis-musrenbang.com, "monvis-musrenbang.com." [Online]. Available: http://monvismusrenbang.com/web/about.php.

[6] R. Prasetianto, Wibowo, and I. Hafidzd, "The Third Information Systems International Conference A Prototype of MonVis-Musrenbang: Monitoring and Visualization Application for Surabaya Development Plan," Open Access J. Inf. Syst.
J. Gurin, "Open Data Now: Big Data vs Open Data - Mapping It Out," 2013. [Online]. Available: http://www.opendatanow.com/2013/11/new-big-data-vs-opendata-mapping-it-out/\#.Vf31SxsVi00.

[8] LABGIS Universitas Andalas, "Mengenal Google Maps.”.

[9] B. Syifa, "Manfaat Google Map." [Online]. Available: http://www.binasyifa.com/929/13/27/manfaat-googlemap.htm/.

[10] C. Kenneth, L. Laudon, and J. P., Management Information Systems Managing The Digital Firm. Salemba Empat, 2008.

[11] Olivera, "Teknik Visualisasi Dalam Data Mining," in Seminar Nasional Informatika, 2003.

[12] Anonymous, "No Title." [Online]. Available: http://repository.upnyk.ac.id/275/1/E-

14_Survey_jurnal__DM_-SeminarUPN'09.pdf. 